\title{
RIBOSOMAL RNA GENES ON HOMOEOLOGOUS CHROMOSOMES OF GROUPS 5 AND 6 IN HEXAPLOID WHEAT
}

\author{
R. B. FLAVELL and M. O'DELL \\ Cytogenetics Department, Plant Breeding Institute, Trumpington, Cambridge CB2 2LQ
}

Received 22.iv.76

\begin{abstract}
Summary
The ribosomal RNA gene contents of wheat aneuploid lines, differing in the numbers of $5 \mathrm{~A}, 5 \mathrm{~B}, 5 \mathrm{D}, 6 \mathrm{~A}, 6 \mathrm{~B}$ and $6 \mathrm{D}$ chromosomes, have been estimated by ribosomal RNA/DNA hybridisation. These and other estimates on intervarietal substitution lines, provide some evidence for ribosomal RNA genes being localised on chromosomes $5 \mathrm{D}$ and $6 \mathrm{~B}$. Chromosome $6 \mathrm{~B}$ of the variety Chinese Spring possesses approximately 5500 rRNA genes, 60 per cent of the total ribosomal RNA gene complement of the variety. In the variety Holdfast, chromosome $6 \mathrm{~B}$ possess approximately 2000 ribosomal RNA genes. This value comes from examining interspecies substitution lines in which chromosomes $6 \mathrm{~A}, 6 \mathrm{~B}$ and $6 \mathrm{D}$ are replaced by rye chromosomes. The approximate number of ribosomal RNA genes on the four nucleolar organiser chromosomes of the variety Chinese Spring are presented.
\end{abstract}

\section{InTRODUCTION}

HeXAPLOID wheat, Triticum aestivum possesses at least four pairs of homologous chromosomes (1A, 1B, 5D and 6B) able to form nucleoli (Crosby, 1957; Longwell and Svihla, 1960; Bhowal, 1972; Darvey and Driscoll, 1972). Since nucleolar organisers are the sites of ribosomal RNA (rRNA) genes (Birnstiel, Ghipchase and Spiers, 1971), these chromosomes would be expected to possess clusters of rRNA genes. We have previously shown (Mohan and Flavell, 1974; Flavell and Smith, 1974 a, $b$; Flavell, 1975) that altering the dosage of these chromosomes in aneuploids changes the number of rRNA genes. Extended studies on chromosomes 1A and 1B (Flavell and Smith, $1974 b$ ) have indicated that the number of rRNA genes on these chromosomes may vary in different wheat varieties but in the variety Chinese Spring, the genetic background of the collection of wheat aneuploids most commonly used (Sears, 1954), chromosome 1A has a very small proportion of the rRNA genes while chromosome $1 \mathrm{~B}$ possesses between 20 and 40 per cent of the rRNA genes in the variety.

This paper describes a more detailed investigation into the number of rRNA genes on chromosomes belonging to homoeologous groups 5 and 6 , i.e. chromosomes $5 \mathrm{~A}, 5 \mathrm{~B}, 5 \mathrm{D}, 6 \mathrm{~A}, 6 \mathrm{~B}$ and $6 \mathrm{D}$. We have again exploited the array of wheat aneuploid lines having the same genetic background (Sears, 1954) and also inter-varietal substitution and addition lines where single chromosomes have been either substituted into or added to a near-constant genetic background (Riley, 1964; Law, 1968; Law and Worland, 1972).

\section{Materials and methods}

(i) Plant genotypes

All the seed was obtained from stocks maintained at the Plant Breeding Institute, Cambridge. The aneuploid stocks of the variety Chinese Spring 
were originally obtained from Dr E. R. Sears, University of Missouri, Golumbia, U.S.A. (Sears, 1954). The substitution lines in which chromosomes $5 \mathrm{~A}, 5 \mathrm{~B}$ and $5 \mathrm{D}$ of the variety Chinese Spring have been replaced one at a time by their homologues from the variety Hope were also obtained from Dr E. R. Sears. The substitution lines, again in a Chinese Spring background, derived from the variety Cheyenne were developed by Dr Rosalind Morris at the University of Nebraska, while the substitution lines from Triticum spelta and Cappelle-Desprez were developed in this Department by Dr C. N. Law (1968; Law and Worland, 1972) and his colleagues. All these substitution lines have had between 5 and 7 backcrosses to Chinese Spring. Duplicate (A and B) lines were studied of the substitution lines involving Triticum spelta, Cappelle-Desprez and Gheyenne chromosomes. The duplicate lines were developed independently from the initial crosses involved in the construction of the inter-varietal substitution lines. The substitution of chromosome $6 \mathrm{R}$ of Secale cereale (rye) variety King II, for chromosomes $6 \mathrm{~A}, 6 \mathrm{~B}$ and $6 \mathrm{D}$ of the wheat variety Holdfast has been described by Riley (1964).

\section{(ii) DNA and ${ }^{3} H$ rRNA purification}

DNA was purified from frozen aerial tissue of 4 to 8 plants of each genotype as described previously (Smith and Flavell, 1974). After treatments with amylase, pancreatic ribonuclease and self-digested pronase, the DNAs were repeatedly shaken with phenol saturated with $0.2 \times \mathrm{SSC}(\mathrm{SSG}=0 \cdot 15 \mathrm{M}$ sodium chloride $0.015 \mathrm{~m}$ sodium citrate) in the presence of 2 per cent sodium lauryl sulphate until no further precipitate appeared at the interface upon centrifugation. The final aqueous layer was dialysed overnight against $0.1 \times \mathrm{SSG}$ at $3^{\circ} \mathrm{C}$ and the DNA recovered by ethanol precipitation or centrifugation at $120,000 \times g$ for 8 hours. DNAs from some genotypes were further purified by banding in preparative caesium chloride gradients (Flamm, Bond and Burr, 1966). Only occasionally is it found that additional purification in caesium chloride gradients produces a significant difference in $\mathrm{rRNA} / \mathrm{DNA}$ hybridisation values.

Tritium labelled rRNA was purified from germinating wheat embryos (variety Chinese Spring) after incubation in ${ }^{3} \mathrm{H}$ uridine exactly as described previously (Mohan and Flavell, 1974). The ${ }^{3} \mathrm{H}$ labelled rRNA had a specific activity of $60,800 \mathrm{cpm} / \mu \mathrm{g}$.

\section{(iii) Hybridisation procedure}

This has been described in detail previously (Mohan and Flavell, 1974). The percentage hybridisation of rRNA to DNA was calculated from the specific activity of the rRNA and the DNA on each filter. All measurements were corrected for the behaviour of filters lacking DNA. At least six replicate filters containing each DNA were incubated together in each experiment. DNA from the variety Chinese Spring was included as a control in all experiments. The results presented are combined results from at least two separate experiments with each genotype. Two different preparations of each of the DNAs from the aneuploid lines but only one preparation from each of the substitution lines was used. The results for aneuploid lines were all corrected for their small differences in DNA content relative to the euploid. The DNA 
contents of individual chromosomes or chromosome arms were calculated from published chromosome arm lengths (Sears, 1954) assuming that DNA content is proportional to chromosome length under similar conditions of chromosome condensation. Standard errors of the mean hybridisation percentages were calculated by analysis of variances. The numbers of genes per $1 C$ genome were calculated from the rRNA/DNA hybridisation percentages assuming the $1 C$ DNA content of hexaploid wheat is $10.65 \times 10^{12}$ daltons and $25 \mathrm{~s}$ and $18 \mathrm{~s}$ rRNA molecules are $1.3 \times 10^{6}$ and $0.7 \times 10^{6}$ daltons respectively.

\section{RESUltS AND DISGUSSION}

The presence of rRNA genes on chromosomes $5 \mathrm{~A}, 5 \mathrm{~B}, 5 \mathrm{D}$ and $6 \mathrm{~A}, 6 \mathrm{~B}$ and $6 \mathrm{D}$ was investigated by $\mathrm{rRNA} / \mathrm{DNA}$ hybridisation using DNAs purified from a range of aneuploid lines with different doses of each of these chromosomes. Three different kinds of aneuploids were investigated. (1) Ditelosomics: these lines contain 40 chromosomes plus one homologous pair of telocentric chromosomes, the short arms having been deleted in every case studied here. (2) Tetrasomics: these lines contain an additional pair of homologous chromosomes. (3) Nullisomics-tetrasomics: these have one pair of homologous chromosomes deleted and a compensating pair of homologous chromosomes present in two doses instead of one. We have also used inter-varietal substitution lines where pairs of homologous chromosomes have been replaced one pair at a time by pairs of chromosomes from other varieties or another species (Law, 1968; Law and Worland, 1972).

\section{(i) Chromosomes $5 A, 5 B$ and $5 D$}

The mean proportions of ribosomal DNA in DNAs isolated from the aneuploid lines with different numbers of chromosomes $5 \mathrm{~A}, 5 \mathrm{~B}$ and $5 \mathrm{D}$ are expressed in fig. 1 relative to the euploid control in each of the experiments.

The only ditelosomic line differing from the euploid control in its rRNA gene content by more than 5 per cent is ditelosomic $5 \mathrm{D}^{\mathrm{L}}$ which has the short arm of chromosome $5 \mathrm{D}$ deleted.

Tetrasomic 5A has a mean rRNA/DNA percentage hybridisation value of 109 per cent, tetrasomic $5 \mathrm{~B}$ has a mean value of 106 per cent while tetrasomic $5 \mathrm{D}$ has a mean value of 59 per cent. None of the nullisomic-tetrasomic lines had rRNA gene contents significantly different from euploid. Overall, there is no evidence that $\mathrm{rRNA}$ gene multiplicity is correlated with the dosage of chromosomes $5 \mathrm{~A}, 5 \mathrm{~B}$ or $5 \mathrm{D}$. The 16 per cent reduction in rRNA gene content in ditelosomic $5 \mathrm{D}^{\mathrm{L}}$ is consistent with the cytological evidence that the short arm of chromosome 5D carries a small nucleolar organiser (Darvey and Driscoll, 1972), but the rRNA gene contents of the nullisomic 5D tetrasomic $5 \mathrm{~A}$ and nullisomic $5 \mathrm{D}$ tetrasomic $5 \mathrm{~B}$ lines do not provide evidence that chromosome $5 \mathrm{D}$ carries any rRNA genes. It is possible that the approximately euploid number of rRNA genes in the nullisomic $5 \mathrm{D}$ tetrasomics is due to the presence of rRNA genes on chromosomes $5 \mathrm{~A}$ and $5 \mathrm{~B}$. However if this is so, the group 5 chromosomes must share a very small proportion of the rRNA genes of the variety Chinese Spring.

The low number of rRNA genes in the tetrasomic 5D line is an anomaly, as found previously (Mohan and Flavell, 1974). Because this deficiency is 
not present in the compensated nullisomic-tetrasomic 5D lines (fig. 1), and there is no elevated level of rRNA genes in lines lacking chromosome 5D, it seems probable that the loss of rRNA genes is due to a deletion of rRNA genes in the genetic background unconnected with the increased dosage of chromosome 5D. It is possible to develop complicated models of the control or rRNA gene multiplicity by a regulatory gene on chromosome $5 \mathrm{D}$ but this
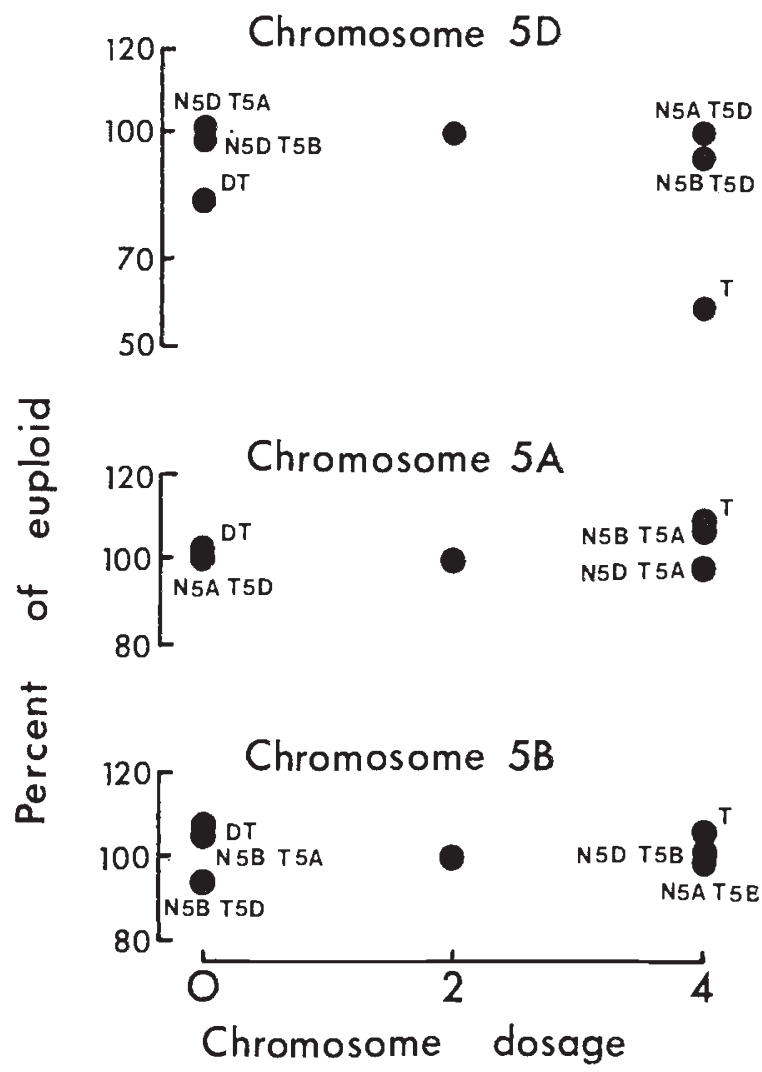

FIG. 1.-Hybridisation of rRNA to DNAs isolated from aneuploid lines with different doses of chromosomes 5A, 5B and 5D. Values are means of at least six replicate filters, expressed relative to the euploid control included in each experiment. $\mathrm{N}=$ Nullisomic; $\mathrm{T}=$ Tetrasomic; DT $=$ Ditelosomic.

seems unwarranted at present. We have previously provided a similar explanation for the anomalously low number of rRNA genes in a ditelosomic line lacking the short arm of chromosome lA (Flavell and Smith, 1974b). These results strongly emphasise the importance of not drawing conclusions about the rRNA gene contents of specific nucleolar organisers where the possibility of variation at other nucleolar organisers cannot be eliminated. This seems especially important in plants where mechanisms clearly exist for very frequently producing natural variation in rRNA gene multiplicity (Timmis, Sinclair and Ingle, 1972; Phillips et al. 1973; Flavell and Smith, 1974a; Cullis and Davies, 1975; Flavell, 1975; Ramirez and Sinclair, 1975). 
Because in different varieties of hexaploid wheat homologous nucleolar organisers may carry different numbers of rRNA genes (Flavell and Smith, $1974 a$; Flavell, 1975) the possibility of rRNA genes residing on homoeologous group 5 chromosomes was also investigated using lines of the variety Chinese Spring with chromosomes 5A, 5B and 5D replaced one at a time by homologous chromosomes from several other varieties. In many cases, two independently derived substitution lines (A and B) involving the same substituted chromosome, were investigated to help assess the uniformity of

\section{TABLE 1}

Hybridisation of $r R \mathcal{N} A$ to DNAs from Chinese Spring and some substitution line homoeologous group 5 derivatives

\begin{tabular}{|c|c|}
\hline Genotype & $\begin{array}{l}\text { Percentage hybridisation* } \\
\text { (Mean of six replicates) }\end{array}$ \\
\hline Chinese Spring (CS) & 0.087 \\
\hline $\begin{array}{l}\mathrm{ACS}-\text { Triticum spelta } 5 \mathrm{~A} \\
\mathrm{BCS}-\text { Triticum spelta } 5 \mathrm{~A}\end{array}$ & $\begin{array}{l}0 \cdot 087 \\
0 \cdot 081\end{array}$ \\
\hline $\begin{array}{l}\text { ACS-Cappelle-Desprez 5A } \\
\text { BCS-Cappelle-Desprez 5A }\end{array}$ & $\begin{array}{l}0.094 \\
0.093\end{array}$ \\
\hline $\begin{array}{l}\text { ACS-Cheyenne 5A } \\
\text { BCS-Cheyenne 5A }\end{array}$ & $\begin{array}{l}0.083 \\
0.079\end{array}$ \\
\hline CS-Hope 5A & 0.078 \\
\hline $\begin{array}{l}\mathrm{ACS}-\text { Triticum spelta } 5 \mathrm{D} \\
\mathrm{BCS}-\text { Triticum spelta } 5 \mathrm{D}\end{array}$ & $\begin{array}{l}0 \cdot 106 \\
0 \cdot 109\end{array}$ \\
\hline $\begin{array}{l}\text { ACS-Cappelle-Desprez 5D } \\
\text { BCS-Cappelle-Desprez 5D }\end{array}$ & $\begin{array}{l}0.095 \\
0.093\end{array}$ \\
\hline $\begin{array}{l}\text { ACS-Cheyenne 5D } \\
\text { BCS-Cheyenne 5D }\end{array}$ & $\begin{array}{l}0.095 \\
0.094\end{array}$ \\
\hline CS-Hope 5D & $0 \cdot 078$ \\
\hline Chinese Spring (CS) & 0.082 \\
\hline $\begin{array}{l}\mathrm{ACS}-\text { Triticum spelta } 5 \mathrm{~B} \\
\mathrm{BCS}-\text { Triticum spelta } 5 \mathrm{~B}\end{array}$ & $\begin{array}{l}0 \cdot 085 \\
0 \cdot 076\end{array}$ \\
\hline $\begin{array}{l}\text { ACS-Cappelle-Desprez 5B } \\
\text { BCS-CCappelle-Desprez 5B }\end{array}$ & $\begin{array}{l}0.071 \\
0 \cdot 077\end{array}$ \\
\hline $\begin{array}{l}\text { ACS-Cheyenne 5B } \\
\text { BCS-Cheyenne 5B }\end{array}$ & $\begin{array}{l}0.086 \\
0.084\end{array}$ \\
\hline CS-Hope 5B & $0 \cdot 082$ \\
\hline
\end{tabular}

* Standard errors of the mean hybridisation percentages ranged from +0.002 to +0.005 . However, only one DNA preparation was used in determining each of these mean percentage hybridisations.

the genetic background of the derived stock. The rRNA/DNA hybridisation percentages for these substitution lines are given in table 1. Only three lines have hybridisation percentages markedly different from the Chinese Spring control. These are the lines in which chromosomes $5 \mathrm{D}$ and $5 \mathrm{~A}$ have been substituted from the variety Hope and the line in which chromosome $5 \mathrm{D}$ has been substituted from Triticum spelta. The small differences in the Hope substitution lines where there are no duplicate lines available must be interpreted with caution, especially since the hybridisation percentages when chromosomes 5D and 5A of Hope are substituted into Chinese Spring 
are lower than the Chinese Spring euploid hybridisation percentage and our measurements on the Chinese Spring aneuploid lines indicate that chromosome 5D of Chinese Spring carries relatively very few rRNA genes (fig. 1). The significantly higher hybridisation percentages when chromosome $5 \mathrm{D}$ of Triticum spelta is substituted into Chinese Spring does support the conclusion that this chromosome carries more rRNA genes than chromosome 5D of Chinese Spring (Flavell and Smith, 1974a).

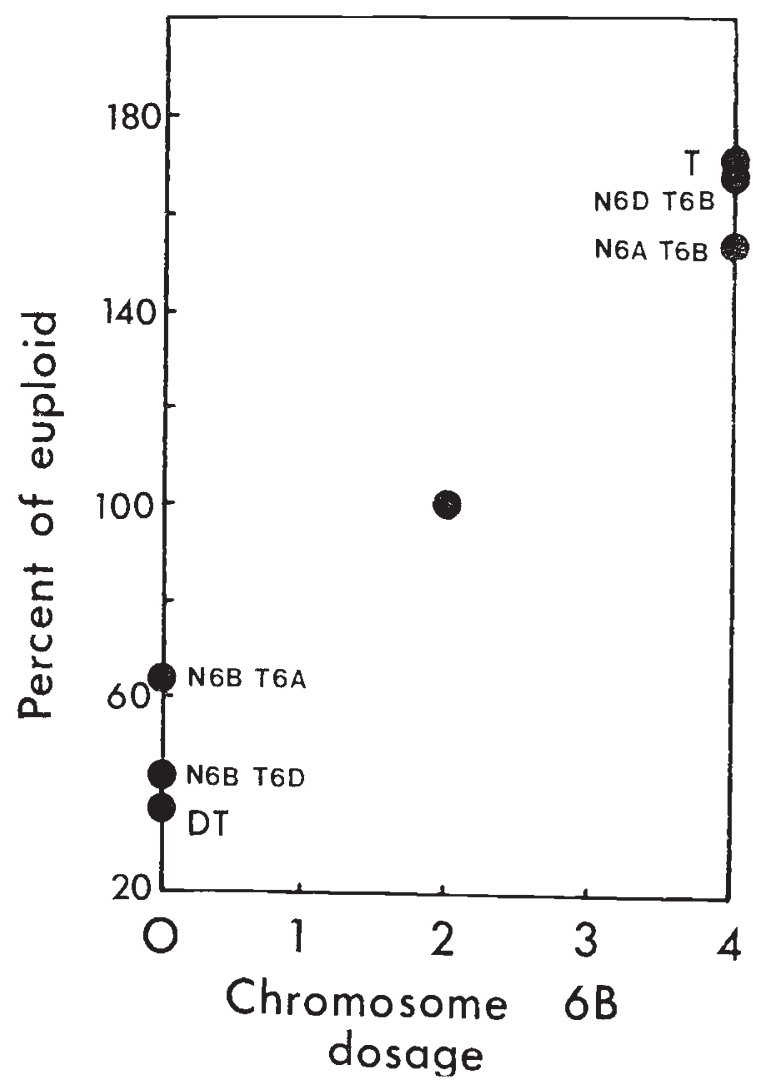

FIG. 2.-Hybridisation of rRNA to DNAs isolated from aneuploid lines with different doses of chromosomes $6 \mathrm{~A}, 6 \mathrm{~B}$ and $6 \mathrm{D}$. Values are means of at least six replicate filters, expressed relative to the euploid control included in each experiment. $\mathrm{N}=$ Nullisomic; $\mathrm{T}=$ Tetrasomic; DT $=$ Ditelosomic.

These studies into whether homoeologous group 5 chromosomes carry rRNA genes have thus provided some evidence that chromosome $5 \mathrm{D}$ carries rRNA genes as would be expected from the cytological evidence for the existence of a nucleolar organiser on chromosome 5D. In the variety Chinese Spring the number of genes on chromosome 5D must be less than 10 per cent of the total number in the genome i.e. $<900$ copies. Similarly if rRNA genes exist on chromosomes $5 \mathrm{~A}$ and $5 \mathrm{~B}$ they must be present in considerably fewer than 900 per chromosome.

Where the possibility exists that there is a very small proportion of the 
total number of rRNA genes on a particular chromosome, the presence or absence of rRNA genes on that chromosome cannot be unequivocally resolved by the methods used in this work. In situ hybridisation may be a better tool for providing a definitive answer.

\section{(ii) Chromosomes $6 A, 6 B$ and $6 D$}

The mean percentages of DNA that hybridise to rRNA in aneuploids with different doses of chromosome $6 \mathrm{~B}$ are shown in fig. 2 . The results are plotted relative to the hybridisation values of the euploid Chinese Spring DNA included as a control in each experiment. There is a strong correlation between the number of $6 \mathrm{~B}$ chromosomes and the percentage of DNA which hybridises to rRNA. The mean line through the data indicates that approximately 60 per cent of the rRNA genes in the variety Chinese Spring reside on chromosome $6 \mathrm{~B}$. Since the ditelocentric line DT $6 \mathrm{~B}^{\mathrm{S}}$ lacking the long arm of chromosome $6 \mathrm{~B}$ has the same number of rRNA genes as euploid (results not illustrated), the rRNA genes on chromosome $6 \mathrm{~B}$ must be on the short arm. This result is in agreement with the cytological evidence that the short arm of chromosome 6B has a nucleolar organiser (Crosby, 1957; Darvey and Driscoll, 1972).

The tetrasomic 6B line lacking chromosome 6A (nullisomic 6A tetrasomic $6 \mathrm{~B}$ ) had significantly lower hybridisation percentages than the tetrasomic $6 \mathrm{~B}$ line, while the nullisomic $6 \mathrm{~B}$-tetrasomic $6 \mathrm{~A}$ line had a higher hybridisation percentage than the ditelosomic $6 \mathrm{~B}^{\mathrm{L}}$ line (fig. 2). This suggests that chromosome $6 \mathrm{~A}$ may possess some rRNA genes.

TABLE 2

Hybridisation of $r R \mathcal{N} A$ to DNAs from Holdfast and some derived genotypes having rye chromosomes substituted or added

\begin{tabular}{lcc}
\multicolumn{1}{c}{ Genotype } & $\begin{array}{c}\text { Chromosome } \\
\text { number }\end{array}$ & $\begin{array}{c}\text { Percentage hybridisation } \\
\text { (Mean } \pm \text { standard error of mean) }\end{array}$ \\
Holdfast & 42 & $0.061 \pm 0.002$ \\
Holdfast 6A/rye 6R & 42 & $0.058 \pm 0.002$ \\
Holdfast 6B/rye 6R & 42 & $0.042 \pm 0.002$ \\
Holdfast 6D/rye 6R & 42 & $0.060 \pm 0.001$ \\
Holdfast +rye 6R & 44 & $0.060 \pm 0.002$
\end{tabular}

The presence of rRNA genes on homoeologous group 6 chromosomes was also investigated in substitution lines derived from the variety Holdfast. In these lines chromosomes $6 \mathrm{~A}, 6 \mathrm{~B}$ and $6 \mathrm{D}$ have been substituted one at a time by the homoeologous chromosome (6R) from the rye variety King II (Riley, 1964). The rRNA hybridisation percentages using DNAs from these lines are shown in table 2 together with the hybridisation percentage of the DNA from an addition line in which this same rye chromosome is present as a disomic addition to the variety Holdfast. The results for the addition line DNA, and the 6A and 6D substitution line DNAs are indistinguishable from that for Holdfast DNA. This suggests that there are no rRNA genes on chromosome $6 \mathrm{R}$ of rye, nor on chromosomes $6 \mathrm{~A}$ and $6 \mathrm{D}$ of Holdfast wheat. When chromosome $6 \mathrm{~B}$ of Holdfast was replaced by chromosome $6 \mathrm{R}$ of rye, 30 per cent of the rRNA genes were deleted. This further supports the conclusion that chromosome $6 \mathrm{~B}$ of wheat carries rRNA genes. 
The variety Holdfast has only approximately 70 per cent of the number of rRNA genes in the variety Chinese Spring (Flavell and Smith, 1974a). Holdfast has approximately $6250 \mathrm{rRNA}$ genes while Chinese Spring has approximately 9150 . From the data in table 2, chromosome $6 \mathrm{~B}$ of Holdfast must possess about 2000 rRNA genes while chromosome $6 \mathrm{~B}$ of Chinese Spring possesses approximately $5500 \mathrm{rRNA}$ genes. This provides yet another illustration of variation in rRNA gene multiplicity on homologous chromosomes within Triticum aestivum (Flavell and Smith, 1974a, b; Flavell, 1975).

In summary, there is good evidence for chromosome $6 \mathrm{~B}$ possessing rRNA genes but no evidence that $6 \mathrm{D}$ carries rRNA genes. Chromosome $6 \mathrm{~A}$ of Chinese Spring may carry some rRNA genes but as indicated for chromosomes $5 \mathrm{~A}$ and $5 \mathrm{D}$ it is difficult to draw definite conclusions using these methods, when only a small proportion of the rRNA gene complement is involved. Darvey and Driscoll (1972) have reported that in the root tips of the nullisomic $6 \mathrm{D}$-tetrasomic $6 \mathrm{~A}$ stock there is a higher mean number of nucleoli per cell and that the tetrasomic $6 \mathrm{~A}$ stock has a higher nucleolar activity at premeiotic interphase than euploid. These results suggest chromosome $6 \mathrm{~A}$ is involved in nucleolar formation but this involvement could be in inducing the nucleolar activity of chromosomes $1 \mathrm{~A}, 1 \mathrm{~B}, 6 \mathrm{~B}$ or $5 \mathrm{D}$ and not necessarily in producing nucleoli from its own organiser.

\section{(iii) The distribution of $r R \mathcal{N} A$ genes in the variety Chinese Spring}

The results reported in this paper on the aneuploid lines of the variety Chinese Spring together with the results published previously (Flavell and Smith, 1974a, b) enable the number of genes on the different nucleolar

TABLE 3

$\begin{gathered}\text { Number of rRNA genes on the different chromosomes of } \\ \text { Chinese Spring }\end{gathered}$
rRNA gene number
rRromosome
6B
1B
1A
5D
6A?
Others?
Total in Chinese Spring

Gene numbers for chromosomes $5 \mathrm{D}$ and $6 \mathrm{~B}$ are from the results in figs. 1 and 2. The numbers for chromosomes $1 \mathrm{~A}$ and $\mathrm{IB}$ are from Flavell and Smith (1974b). In the latter results, different aneuploid stocks suggested significantly different numbers of rRNA genes for chromosome IB of Chinese Spring (see discussion in Flavell and Smith, $1974 b$ and Flavell, 1975). The 2700 rRNA genes in table 3 is an average value.

organiser chromosomes of the variety Chinese Spring to be estimated separately. These are shown in table 3. The numbers of genes have been calculated from the hybridisation percentages.

Since few genes could be detected on chromosomes IA (Flavell and Smith, 1974b) and 5D (fig. 1), these chromosomes probably have fewer than 1000 genes between them. Some rRNA genes may be on chromosome $6 \mathrm{~A}$ or other chromosomes not studied. However most of the rRNA genes 
(60 per cent) are on chromosome $6 \mathrm{~B}$ with about 30 per cent on chromosome $1 B$ (Flavell and Smith, 1974b).

Chromosomes $1 \mathrm{~A}$ and 5D produce only very small nucleoli or none at all in the variety Chinese Spring. This is consistent with the chromosomes having only a very small proportion of the total rRNA gene complement. However, nucleolar expression cannot simply be a reflection of the number of rRNA genes clustered at the organiser site since the chromosome 1B organisers are "stronger" than the chromosome 6B organisers (Longwell and Svihla, 1960). In Chinese Spring root tips, 1B chromosomes make larger nucleoli than 6B chromosomes (Darvey and Driscoll, 1972) even though they have only half as many rRNA genes as chromosome 6B (table 3 ).

Acknowledgments.-We are grateful to Dr Colin Law and Professor Ralph Riley of this Institute for critically reading the manuscript.

\section{REFERENCES}

BiRNSTIEL, M. L., Chipchase, M., AND sPiers, J. 1971. The ribosomal RNA cistrons. Progress in Nucleic Acid and Molecular Biology, 11, 351-389.

Bноw AL, J. G. 1972. Nucleolar chromosomes in wheat. Z. Pflanzenzuch., 68, 253-257.

CrosBy, A. R. 1957. Nucleolar activity of lagging chromosomes in wheat. Am. F. Bot., 44, 813-822.

Gullis, C. A., AND Davies, D. R. 1975. Ribosomal DNA amounts in Pisum sativum. Genetics, $81,485-492$

DARVEY, N. L., AND DRIscoll, C. J. 1972. Nucleolar behaviour in Triticum. Chromosoma (Berl.), 36, 131-139.

FLAMM, w. G., BOND, H. E., AND BURR, H. E. 1966. Density gradient centrifugation of DNA in a fixed angle rotor. Biochim. Biophys. Acta, 129, 310-319.

FLAVELL, R. B. 1975. Quantitative variation in nucleolar ribosomal RNA gene multiplicity in wheat and rye. Proc. 2nd Fohn Innes Symposium., 53-62.

FLAVELL, R. B., AND SMITH, D. B. 1974a. Variation in nucleolar organiser rRNA gene multiplicity in wheat and rye. Chromosoma (Berl.), 47, 327-334.

FLAVELL, R. B., AND SMITH, D. B. 1974b. The role of homoeologous group 1 chromosomes in the control of rRNA genes in wheat. Biochem. Genet., 12, 271-279.

LAW, c. N. 1968. The development and use of intervarietal chromosome substitution. European Wheat Aneuploid Cooperative Newsletter, 1, 22-23.

LAW, C. N., AND WORLAND, A. J. 1972. Aneuploidy in wheat and its uses in genetic analysis. Report of Plant Breeding Institute, Cambridge, 25-65.

LONGWELl, A. G., AND SVIHLA, G. 1960. Specific chromosomal control of the nucleolus and of the cytoplasm in wheat. Exp. Cell Res., 20, 294-312.

MOHAN, J., AND FLAVELL, R. B. 1974. Ribosomal RNA cistron mulitplicity and nucleolar organizers in hexaploid wheat. Genetics, 76, 33-44.

PHILlips, R. L., WANG, S. S., WEBER, D. F., AND KLEESE, R. A. 1973. The nucleolar organiser in maize. Genetics, 74, S 212.

RAMIREZ, S. A., AND SINCLAIR, J. H. 1975. Intraspecific variation of ribosomal gene redundancy in Zea Mays. Genetics, 80, 495-504.

RILEY, R. 1964. Cytogenetics and plant breeding. Genetics Today, 3, 681-688.

SEARs, E. R. 1954. The aneuploids of common wheat. Missouri Agricultural Experimental Station Research Bulletin, 572, 1-59.

SMITH, D. B., AND FLAVELL, R. B. 1974. Occurrence, relatedness and evolution of repeated nucleotide sequences in the genomes of some Graminae species. Biochem. Genet., 12, 243-256.

TIMMIs, J. N., SINCLAIR, J., AND INGLE, J. 1972. Ribosomal RNA genes in euploids and aneuploids of hyacinth. Cell differentiation, 1, 335-339. 